\title{
Analysis Of Potential And Development Strategy Of Halal Tourism Of The Pulau Santen Banyuwangi
}

\author{
Agus Mahardiyanto ${ }^{1}, \mathrm{M}$ Fathorrazi $^{2}$ \\ \{agusmahardiyanto.feb@unej.ac.id ${ }^{1}$, m.fathorrazi@yahoo.co.id\}
}

Sharia Economics Department Faculty Of Economics and Business University Of Jember ${ }^{12}$

\begin{abstract}
The global halal industry grow up rapidly. Data on the global halal industry is estimated to reach USD 2.3 trillion. This Data is expected to continue to increase. The growth in the number of Muslims and awareness of halal positive values for both Muslims and non-Muslims has a significant impact on improving the global halal market. Halal tourism is part of the halal market consisting of halal pharmaceuticals, halal food, halal fashion, halal tourism and halal logistics. This research try to analyze the potential of Halal Tourism in the Pantai Syariah Pulau Santen Banyuwangi and development strategies. Use a qualitative approach to data collection methods through observation, documentation and in-depth interviews with tourists, tourism agents, tourism agencies and Focus Group Discussion (FGD) then data reduction, data coding and data interpretation are carried out. Validity test is carried out by triangulating the data in the hope that the best strategy model is obtained for the development of Pantai Syariah Pulau Santen Banyuwangi. The results of the research show that the Pantai Syariah Pulau Santen Banyuwangi has the potential to be developed into a sharia tourist destination, however, it needs to improve the facilities and others.
\end{abstract}

Keywords: Tourism Potential, Strategy, Pantai Wisata Syariah Pulau Santen Banyuwangi.

\section{Pendahuluam}

Potensi industri Halal terus berkembang sampai hari ini, perkembangan tersebut menunjukkan potensi sektor industri halal merupakan sektor yang menjanjikan. Industri halal global diperkirakan nilainya mencapai USD 2.3 Triliun (Global Halal Industry An Overview, Chapter 13 p.140). Industri halal dipandang sebagai industri dengan pertumbuhan tercepat. Malaysia International Islamic Finance Center (MIFC) memperkirakan bahwa pada tahun 2018 sebesar USD 6.4 Triliun. Beberapa sektor industri halal yang berkembang diantaranya makanan halal, Industri farmasi halal, logistic halal, pariwisata syariah, kosmetik, jasa dan beberapa industri lain yang terus tumbuh pesat.

Perkembangan industri halal tidak bisa dilepaskan dari jumlah warga muslim global yang terus meningkat. populasi muslim secara global diperkirakan tumbuh sekitar 3\% pertahun. Total populasi muslim diperkirakan mencapai $23 \%$ dari populasi penduduk global atau sekitar 1.8 miliar jiwa (Global Halal Industry An Overview, Chapter 13 p.140). Tren ini terus meningkat, dimana pertumbuhan populasi muslim ini diperkirakan akan mencapai 2.2 miliar pada tahun 2030 (Majlisglobal, P.2).

Warga muslim menilai bahwa perintah untuk mengkonsumsi halal merupakan syariat agama islam yang harus ditaati. Maka dari itu semua yang dikonsumsi oleh umat muslim 
harus halal, tanpa ada sedikit pun terkontaminasi oleh yang haram. Dengan tingkat kesadaran yang terus meningkat tentu akan diiringi dengan semakin meningkatnya konsumsi halal di kalangan muslim.

Keseriusan dalam kampanye dan membangun pariwisata halal di Indonesia yang dilakukan oleh Kementrian Pariwisata dan Ekonomi Kreatif memperoleh apresiasi dari dewan World Halal Tourism Awards tahun 2016 sehingga Indonesia memperoleh 12 kategori penghargaan dalam acara World Halal Tourism Awards yang diselenggarakan di Abu Dhabi. (Kemenpar, 2016).

Pariwisata alam dengan konsep syariah yang dikembangkan oleh Pemkab Banyuwangi adalah Pantai Syariah Pulau Santen, Pantai tersebut terdapat di Kecamatan Rogojampi Banyuwangi atau tepatnya disebelah utara Pantai Cemara. Konsep pariwisata syariah ini diambil sebagai jawaban atas besarnya potensi pasar muslim yang ada secara global dan di Indonesia. Pulau Santen sendiri sebagai destinasi wisata syariah baru diresmikan bulan Maret 2017 kemarin atau hampir bersamaan dengan rencana kedatangan Raja Salman ke Indonesia.

Data Dinas Kebudayaan dan Pariwisata Banyuwangi bahwa Jumlah kunjungan wisatawan tahun 2013 mencapai 874.285 Jiwa selama tahun 2016mencapai 3 juta orang atau meningkat 300 persen lebih dibandingkan tahun 2013 yang mencapai 874.285 orang (1). Selama tahun 2016 juga tercatat kunjungan wisatawan mancanegara sebesar 75.000 wisman.

\section{Literatur Review}

Pariwisata syariah secara definisi masih belum memiliki definisi yang tetap dan disepakati oleh semua pihak, merujuk dari Peraturan Menteri Pariwisata Dan Ekonomi Kreatif Tahun 2014 Tentang Hotel Syariah bahwa masih terjadi perdebatan tentang penggunaan istilah syariah atau halal dalam penerapannya. Dalam peraturan tersebut diklasifikasikan hotel syariah sesuai standar Hilal 1 dan Hilal 2, semakin tinggi tingkat Hilal berarti semakin memenuhi standar halal di hotel tersebut.

Secara Definisi Pariwisata Syariah, Halal Tourism dan Islamic Tourism memiliki kesamaan berupa ketaatan umat muslim dalam menjaga perilakunya dalam berwisata sesuai dengan kaidah agama dengan tetap memperhatikan kaidah leisure (kesenangan) sebagai tujuan utama dalam berwisata.

Riset dalam tulisan ini mencoba untuk menganalisis potensi pariwisata syariah yang ada di Pantai Wisata Syariah Pulau Santen Banyuwangi Dan Strategi Serta Upaya Pengembangannya.

\section{Metode Penelitian}

Penelitian ini menggunakan data kualitatif dengan pendekatan eksploratori riset. keterbatasan informasi tentang objek penelitian yang menyebabkan dipilihnya desain eksploratori untuk mengetahui obyek penelitian dan informasi terbaru yang ada didalamnya (2). Penelitian kualitatif memungkinkan untuk mendapatkan hasil penelitian yang lebih mendalam dan detail terhadap obyek penelitian (3). Metoda pengumpulan data menggunakan 
kajian literatur dan wawancara mendalam kepada Dinas Pariwisata Banyuwangi. Pokdarwis dan pengunjung Pantai Wisata Syariah Pulau Santen. Tahapan analisis data dalam penelitian ini berdasarkan tahapan dalam riset kualitatif (4).

\subsection{Metode Penelitian Strategi Pengembangan Pantai Syariah Pulau Santen}

Strategi pengambangan Pantai Wisata Syariah Pulau Santen dirumuskan melalui 3 metoda, yakni: melalui Dinas Pariwisata, Pengelola Pantai Wisata Syariah Pulau Santen (Pokdarwis) dan Pengunjung pantai. Tiga elemen ini yang akan didalami responnya saat mengunjungi pantai syariah dengan harapan kedepan pantai ini agar menjadi destinasi yang sesuai dengan harapan pengelola, pengunjung dan dinas terkait.

\subsubsection{Dinas Pariwisata}

Dinas Pariwisata sebagai bagian sentral dalam pengembangan Pantai Wisata Syariah Pulau Santen terus mengupayakan inovasi di dalam pengembangan pariwisata di Banyuwangi. Salah satunya adalah memunculkan Brand (merek) Syariah.

Hasil wawancara dengan kedua pihak terdapat dua jawaban yang memiliki benang merah yang saling terkait. dalam pengembangan pantai Syariah Pulau Santen dimana keduanya memiliki kesamaan sebagai destinasi pariwisata yang ditujukan untuk wisatawan muslim dengan membawa label (Brand) Syariah didalamnya. Dalam hal ini pantai pulau Santen pernah menjadi salah satu rencana objek pariwisata yang diharapkan menjadi salah satu persinggahan raja Arab Saudi waktu berkunjung ke Indonesia. Dimana Peresmian pantai Syariah Pulau Santen dan Kedatangan Raja Saudi di Indonesia berdekatan di Bulan yang sama pada Maret 2017.

\subsubsection{Pengunjung}

Pengunjung Pantai Syariah Pulau Santen menjadi salah satu dari ketiga elemen (Dinas pariwisata, Pokdarwis, Pengunjung) yang akan didalami respon mereka saat mengunjungi Pantai Syariah Pulau Santen, dengan harapan terdapat kesinambungan antara pengelola dan pengunjung sehingga tercipta suasana pantai yang kondusif sesuai harapan pengunjung dengan tetap menjaga kesyariahan pantai ini.

\subsubsection{Fasilitas}

Fasilitas menjadi titik sentral yang perlu diperhatikan dalam pengembangan Pantai Wisata Syariah Pulau Santen Banyuwangi diantaranya keberadaan Mushola, Tempat wudhu, Toilet, Gazebo/Pondok dan Tempat parkir, Penunjuk arah, Pusat informasi yang mendukung sarana Pantai Wisata Syariah Pulau Santen Banyuwangi. Dalam hal ini Pantai Wisata Syariah Pulau Santen Banyuwangi masih perlu meningkatkan sarana dan fasilitasnya:

Hasil wawancara dengan responden dan Pokdarwis terdapat benang merah bahwa fasilitas di Pantai Wisata Syariah Pulau Santen Banyuwangi masih perlu dibenahi dan ditambah. Beberapa titik sentral krusial adalah:

a. Mushola, sebagai simbol Pantai Wisata Syariah Pulau Santen Banyuwangi yang membawa label Syariah, ini menjadi satu indikasi penting bahwa terkait dengan fasilitas 
ibadah dan yang mendukung peribadatan tentunya harus diperhatikan oleh pengelola Pantai Wisata Syariah Pulau Santen Banyuwangi, Mushola di pantai ini tampak kotor dan kurang terawat, karpet dan sajadah pun ada dan akan digelar kalau ada pengunjung yang hendak sholat disana.

b. Toilet, Sarana pendukung lainnya adalah Toilet dan atau Kamar Mandi. Sebagai pantai yang membawa label Syariah toilet sebagai bagian integral dari tempat bersuci juga perlu diperhatikan.

c. Tempat Parkir, Tempat Parkir, sedemikian pentingnya tempat parkir dalam suatu objek wisata sehingga dapat membantu keberlagsungan pengunjung dalam menikmati ketenangan liburanya. Di Pantai Wisata Syariah Pulau Santen Banyuwangi sudah tersedia tempat parkir kendaran yang kondisinya sudah cukup baik. Untuk kendaraan roda dua bisa melewati jembatan untuk menuju pantai sehingga parkiran terletak tidak jauh dari pantai.

d. Pusat Informasi, Pusat informasi merupakan hal penting yang harus ada dalam sebuah tempat pariwisata, Hasil wawancara dengan para pengunjung tersebut menunjukkan bahwa, Pusat Informasi telah tersedia meskipun masih menjadi satu dengan petugas parkir dan keamanan, pentingnya pusat informasi ialah agar memudahkan pengunjung untuk mendapatkan info lengkap dan cepat tentang kondisi pantai syariah pulau santen dan juga terkait dengan keamanan pengunjung bilamana terjadi perubahan kondisi pantai secara mendadak agar cepat tersampaikan kepada para pengunjung.

e. Warung, merupakan tempat yang tidak terlepas dari sebuah tempat pariwisata begitupun di Pantai Wisata Syariah Pulau Santen Banyuwangi yang memiliki warung disekitar pantai. Warung yang tersedia di Pantai Wisata Syariah Pulau Santen Banyuwangi sudah lamayan banyak terletak di sebelah kanan sekitar pantai atau disekitar rumah penduduk, tempatnya pun sudah lumayan baik dan bersih namun belum adanyaa warung yang disebalah kanan pantai.

f. Pondok/ Gazebo, Wisatawan membutuhkan Gazebo yang nyaman. Hasil Wawancara dengan para pengunjung menunjukkan bahwa, telah terdapat Gazebo di pinggir pantai yang penting sebagai tempat istirahat dan bercengkrama dengan keluarga saat berlibur. Akan tetapi, Gazebo tersebut hanya tersedia 1 buah saja, tentunya hal ini perlu ditambah, apalagi saat kondisi siang hari pantai mulai panas, sangat dibutuhkan sekali Gazebo sebagai tempat beristirahat dan berteduh.

g. Penunjuk Arah Menuju Pantai, harus jelas dalam pemasangan rambu-rambu menuju lokasi pantai karena sangat dibutuhakan wisatawan yang akan menuju objek wisata di Pantai Wisata Syariah Pulau Santen Banyuwangi. Rambu-rambu penunjuk jalan di Pantai Wisata Syariah Pulau Santen Banyuwangi sudah ada dan terpasang di sepanjang jalan menuju lokasi wisata.

h. Jembatan, Pantai Syariah Pulau Santen ialah pantai dengan nuansa berbeda karena dipisahkan dengan sungai, dimana untuk mencapainya perlu menyeberangi jembatan. Di Pantai Syariah Pulau Santen, jembatan terbuat dari kayu, dicat penuh warna-warni yang sangat Instagrammable Hasil wawancara dengan pengunjung menunjukkan bahwa, Jembatan di Pantai Syariah menarik untuk dijadikan sebagai objek swafoto, jembatan tersebut menghubungkan antara tempat parkiran mobil dan objek pantai, jembatan ini juga telah di cat warna-warni sehingga menarik untuk dijadikan objek swafoto, di ujung barat dan kanan-kiri terdapat pohon-pohon bakau yang semakin menambah asri jembatan ini.

i. Kebersihan, merupakah salah satu faktor kenyaman pengunjung dalam menikmati liburanya di tempat wisata. kondisi kebersihan di Pantai Wisata Syariah Pulau Santen 
Banyuwangi masih kurang begitu bersih. Di pantai masih terdapat sampah-sampah plstik maupun ranting pepohonan. Sampah-sampah tersebut berasal dari muara sungai yang juumlahna 8 sungai dan akhinya sampah tesebut menumpuk di tepian pantai.

j. Spot Foto, Pentingnya spot foto bagi pengunjung. Terdapat istilah populer di kalangan millenial hari ini "No Picture is Hoax". Berikut Hasil wawancara dengan pengunjung tentang keberadaan spot foto. baik yang alami maupun buatan akan tetapi, spot foto tersebut perlu ditambah agar lebih menarik.

k. Batasan Pengunjung Laki-laki dan Perempuan. berfungsi untuk memisahkan pengunjung objek Pantai Wisata Syariah Pulau Santen Banyuwangi yaitu sebelah kiri khusus untuk perempuan dan sebelah kanan untuk laki-laki atau bebas.

\section{Kesimpulan}

Pantai Wisata Syariah Pulau Santen merupakan pantai yang membawa nama (brand) Syariah Islam didalamnya, sebagai upaya merebut hati para konsumen muslim dan sebagai bagian dari pembeda yang memiliki keunikan tersendiri (differentiation and uniqueness) dengan destinasi wisata pantai yang lain, Pantai ini masih perlu upaya perbaikan dibeberapa sektor misal terkait kebersihan, fasilitas dan ketaatan terhadap syariat itu sendiri, kedepan keseriusan dari Dinas dan Pokdarwis sebagai operator pengelola pantai perlu koordinasi terencana, terarah dan terukur yang tentunya bisa melibatkan pengunjung pantai untuk mendalami harapan dan keinginan para pengunjung agar pantai Syariah kedepan sesuai dengan harapan pengunjung dengan tetap menjaga nuansa syariahnya.

\section{Saran}

Pantai Wisata Syariah Pulau Santen merupakan pantai yang membawa nama (brand) Syariah Islam didalamnya, sebagai upaya merebut hati para konsumen muslim dan sebagai bagian dari pembeda yang memiliki keunikan tersendiri (differentiation and uniqueness) dengan destinasi wisata pantai yang lain, Pantai ini masih perlu upaya perbaikan dibeberapa sektor misal terkait kebersihan, fasilitas dan ketaatan terhadap syariat itu sendiri, kedepan keseriusan dari Dinas dan Pokdarwis sebagai operator pengelola pantai perlu koordinasi terencana, terarah dan terukur yang tentunya bisa melibatkan pengunjung pantai untuk mendalami harapan dan keinginan para pengunjung agar pantai Syariah kedepan sesuai dengan harapan pengunjung dengan tetap menjaga nuansa syariahnya. 


\section{References}

1. Dinas Kebudayaan dan Pariwisata Banyuwangi. Diakses 14 Juni 2018. Available from: www.disbudparbanyuwangi.go.id dan www.banyuwangikab.go.id

2. Mansouri S. "Role of Halal Tourism Ideology in Destination Competitiveness: A Study on Selected Hotels in Bangkok, Thailand". International Conference on Law, Education and Humanities (ICLEH'14) Jan. 30-31, 2014 Pattaya (Thailand). 2014; Available from: dx.doi.org/ 10.15242/ ICEHM.ED0114528

3. Kovjanic G. Islamic tourism as a factor of the Middle East regional development. Turizam. 2014;18(1):33-43.

4. Creswell JW. Research Design, Pendekatan Metode Kualitatif, Kuantitatif, dan Campuran (Terjemahan). Yogyakarta: Pustaka Pelajar. 2016. 85-100 p. 